\title{
Immunological mechanisms explaining the role of vaccines, IgE, mast cells, histamine, elevating ferritin, IL-6, D-dimer, VEGF levels in COVID-19 and dengue, potential treatments such as mast cell stabilizers, antihistamines: Predictions and confirmations
}

\author{
Vinu Arumugham \\ Oct 2020 \\ vinucubeacc@gmail.com
}

\begin{abstract}
A novel coronavirus, SARS-CoV-2 was identified in Wuhan, China. The disease caused by the virus can range in severity from asymptomatic to acute respiratory distress syndrome (ARDS) and death.

Primary dengue infection results in IgE mediated sensitization against dengue virus proteins. These IgE bind to receptors on mast cells. Upon subsequent exposure to the antigen recognized by the IgE, mast cell degranulation occurs releasing mediators such as histamine. Therefore secondary dengue infection results in urticaria, increased vascular permeability, hypotension, dengue hemorrhagic fever and dengue shock syndrome. A case of "slow rolling anaphylaxis".

Vaccines contain proteins derived from coronavirus infected animals as well as other proteins with high homology to SARS-CoV-2. So one could develop IgE mediated sensitization to SARS-CoV-2-like proteins. Therefore, receipt of such vaccines acts like a dengue "primary infection". It results in IgE mediated sensitization. Subsequent SARS-CoV-2 infection becomes a "secondary dengue infection" that has a severe course due to IgE mediated mast cell degranulation and the immune cascade that follows.

There are many common observations between COVID-19 and dengue. Elevated levels of ferritin, interleukin-6, vascular endothelial growth factor, D-dimer, coagulopathy, urticaria and ARDS are reported in both diseases. Numerous teams have now confirmed this mechanism that was predicted in Jan 2020, upon analyzing the 2019-nCoV proteome.

There are many indicators that mast cell degranulation and histamine release have a major role in COVID-19, dengue and influenza severity. Mast cell stabilizers, antihistamines and anti-parasite treatments may address different aspects of this cascade and thus reduce disease severity.
\end{abstract}

\section{Keywords}

Anaphylaxis, COVID-19, dengue, vaccine, antihistamines, mast cell stabilizers 


\section{Introduction}

A novel coronavirus, now named SARS-CoV-2 was identified in hospitalized patients in Wuhan, China, in December 2019. The disease caused by the virus, now named COVID-19, can range in severity from asymptomatic to acute respiratory distress syndrome (ARDS) and death. As will be detailed in the sections below, influenza vaccines cause IgE mediated sensitization (induction of allergy) directed against the influenza virus. Upon subsequent influenza infection, the course of the disease is severe because of a concurrent allergic reaction. This immunopathology was understood and described in 2018 (Arumugham 2018). Based on this understanding, the same immunopathology was predicted for COVID-19, in Jan 2020, when the SARS-CoV-2/2019-nCoV proteome became available for analysis. The treatment for COVID-19 severity is the same as for any other allergic reaction. It includes mast cell stabilizers and histamine blockers such as famotidine and cetirizine. Since then numerous research teams have confirmed these predictions.

\section{Prediction of COVID-19 immunopathology}

Primary dengue infection results in immunoglobulin E (IgE) mediated sensitization directed against dengue virus (DENV) proteins (Míguez-Burbano et al. 1999; Koraka et al. 2003). These IgE antibodies bind to high affinity FceR1 receptors on mast cells. Upon subsequent exposure to the antigen recognized by the IgE, cross-linking of antibodies will result in mast cell degranulation and release of mediators such as histamine. The same process occurs with IgE bound to basophils. Therefore secondary dengue infection results in such mast cell degranulation, histamine release, leading to urticaria, increased vascular permeability, hypotension, dengue hemorrhagic fever (DHF) and dengue shock syndrome (DSS). It can be viewed as a type 1 immediate hypersensitivity reaction (Justiz Vaillant and Zito 2018) with the difference that the antigen exposure is not a step function (as in say food allergy) but a ramp function as the viral replication ramps up over a few days. As a result, we have a "slow rolling anaphylaxis".

Influenza vaccines cause IgE mediated sensitization to influenza viral proteins (Davidsson et al. 2005; Smith-Norowitz et al. 2011; Nakayama et al. 2015; Nagao et al. 2016; Kim et al. 2020). Upon subsequent infection with an influenza virus that has the same or similar proteins, due to cross-reaction we have mast cell degranulation as in the case of dengue. The course of the infection is worse because we have a viral infection concurrent with an allergic reaction. As the viral load increases, so will the severity of the allergic reaction, leading to influenza shock syndrome (Arumugham 2018).

This concept can be generalized. Any population where a new virus/bacteria is introduced, can suffer severe disease if the population has prior IgE mediated sensitization directed against epitopes that have homology to epitopes in the novel pathogen. In nature, IgE mediated sensitization is directed against helminth/parasite antigens. However, now, for the vast majority of the world's population, helminth and parasite infections are rare. The main cause of IgE mediated sensitization is vaccines (Arumugham 2015). Most injected proteins can be expected to cause IgE mediated sensitization and an allergic reaction/anaphylaxis upon subsequent exposure. As Nobel Laureate Charles Richet said more than a hundred years ago, "It would be of more interest now to find a protein which does not produce anaphylaxis than to find one that does." (Richet 1913) Therefore, upon reports of SARS-CoV-2 and the availability of the virus proteome in Jan 2020, BLASTP (Altschul et al. 1997) protein sequence analysis was performed comparing SARS-CoV-2 proteome to the proteomes of organisms used in vaccine manufacturing. The strongest match was to a pig spike protein (from a coronavirus infected pig) as shown in Table 1. 
Not surprisingly, that pig spike protein also has high homology to SARS and MERS virus spike proteins (data not shown).

Since vaccines contain animal proteins derived from pigs (porcine gelatin), cows (bovine serum albumin) infected with any number of viral diseases, one could develop IgE mediated sensitization to numerous viral proteins including coronavirus proteins. We have entire, viable porcine circoviruses in the rotavirus vaccines, for example (CDC 2015). And of course, this is not limited to porcine material. Vaccine manufacturing derives materials from bovine, chicken and other animal sources as well. Therefore, receipt of such vaccines acts like a dengue "primary infection". It results in IgE mediated sensitization directed against coronavirus or coronavirus-like proteins. Once sensitized, a SARS-CoV-2 infection therefore now becomes the equivalent of a secondary dengue infection due to cross-reacting IgE antibodies and similarly can have a severe course for the same reason - IgE mediated mast cell degranulation and the immune cascade that follows. Of course, it is not just coronavirus proteins but vaccines are contaminated with many other proteins that have high homology to SARS-CoV-2 proteins. Purification steps only reduce the concentration of non-target antigens. They are not eliminated. So a diphtheria, tetanus, acellular pertussis (DTap) vaccine can contain all antigens from those organisms, in residual quantities. By definition, a contaminant means we don't know which vaccine lots from which vendors are contaminated with how much of the contaminants. Egg protein contamination amounts in the influenza vaccines are known to vary over a 100-fold among lots, vendors and year of manufacture (Goldis et al. 2010). This means some people will be sensitized and others may not. A game of Russian roulette. This explains why some suffer severe COVID-19 immunopathology and others have asymptomatic disease. In other words, immunopathology in COVID-19 is of iatrogenic origin and not any natural defect in the human immune response to SARS-CoV-2.

Table 1 BLASTP match scores of protein sequence analysis comparing vaccine antigens with SARSCoV-2 proteins

\begin{tabular}{|c|c|c|c|}
\hline Vaccine & Vaccine antigens & SARS-CoV-2 protein & BLASTP score \\
\hline $\begin{array}{l}\text { Multiple vaccines } \\
\text { use infected animal } \\
\text { derived tissues }\end{array}$ & $\begin{array}{l}\text { QGV12786 spike protein [Sus } \\
\text { scrofa] (from a coronavirus } \\
\text { infected pig) }\end{array}$ & $\begin{array}{l}\text { QHD43416 surface glycoprotein } \\
\text { [Severe acute respiratory } \\
\text { syndrome coronavirus 2] }\end{array}$ & 322 \\
\hline DTap/Tdap & $\begin{array}{c}\text { CPP87293.1 putative DNA } \\
\text { helicase [Bordetella pertussis] }\end{array}$ & $\begin{array}{l}\text { QHD43415.1 orf1ab polyprotein } \\
\text { [Severe acute respiratory } \\
\text { syndrome coronavirus 2] }\end{array}$ & 55.5 \\
\hline DTap/Tdap & $\begin{array}{c}\text { WP_023438321.1 ADP-ribose- } \\
\text { binding protein [Clostridium } \\
\text { tetani] }\end{array}$ & $\begin{array}{l}\text { QHD43415.1 orf1ab polyprotein } \\
\text { [Severe acute respiratory } \\
\text { syndrome coronavirus 2] }\end{array}$ & 41.6 \\
\hline Influenza vaccine & $\begin{array}{c}\text { XP_025008461.1 poly [ADP- } \\
\text { ribose] polymerase } 14 \text { isoform } \\
\text { X3 [Gallus gallus] }\end{array}$ & $\begin{array}{l}\text { QHD43415.1 orf1ab polyprotein } \\
\text { [Severe acute respiratory } \\
\text { syndrome coronavirus 2] }\end{array}$ & 60.1 \\
\hline Influenza vaccine & $\begin{array}{l}\text { XP_015131826.1 protein } \\
\text { ZGRF1 [Gallus gallus] }\end{array}$ & $\begin{array}{l}\text { QHD43415.1 orf1ab polyprotein } \\
\text { [Severe acute respiratory } \\
\text { syndrome coronavirus 2] }\end{array}$ & 55.5 \\
\hline
\end{tabular}


Table 1 shows the BLASTP match scores between multiple vaccine antigens and SARS-CoV-2 proteins.

An influenza virus nucleoprotein contaminating the Pandemrix vaccine, induced antibodies that crossreacted with the human hypocretin receptor to cause narcolepsy. That can be used as a baseline to assess cross-reactivity potential. Nucleocapsid protein [Influenza A virus (A/reassortant/NYMC X179A(California/07/2009 x NYMC X-157)(H1N1))] ADE29096.1 vs. human hypocretin receptor 2 (HCRTR2) produces a BLASTP score of 19.7. This level of cross reactivity resulted in the Pandemrix vaccine-induced narcolepsy (Ahmed et al. 2015). As seen in Table 1, the scores are much higher. And the entries listed are just the top vaccine antigen matches. There are of course numerous matches with a score greater than 19.7 .

Public health authorities in the United States including the Food and Drug Administration (FDA), Centers for Disease Control (CDC), the National Institutes for Health (NIH), the European Medicines Agency (EMA), the United Kingdom's Medicines and Healthcare products Regulatory Agency (MHRA), the World Health Organization (WHO), doctors/researchers at many top universities, research centers, news organizations were all notified around Jan 2020 regarding the immunopathology involved in COVID-19 severity and the use of antihistamines and mast cell stabilizers to treat it.

\section{Similarity between COVID-19 and dengue}

There are now multiple reports from dengue endemic areas that COVID-19 is being mistakenly diagnosed as dengue (Yan et al. 2020; Joob and Wiwanitkit 2020). Given the reasons above, there is good reason to expect such similarity.

In COVID-19, elevated levels of ferritin (Mehta et al. 2020), interleukin-6 (IL-6)(Mehta et al. 2020), vascular endothelial growth factor (VEGF) (Zhang et al. 2020a) and D-dimer (Zhang et al. 2020b), have been reported. Elevated levels of ferritin (Van de Weg et al. 2014), IL-6 (Rachman and Rinaldi 2006) , VEGF (Mutiara et al. 2019) and D-dimer (Orsi et al. 2013; Sridhar et al. 2017; Mutiara et al. 2019) are also reported with dengue infection. Coagulopathy is reported in both COVID-19 (Zhang et al. 2020b) and dengue (Rachman and Rinaldi 2006). Urticaria is reported in both (Chuamanochan 2019; Joob and Wiwanitkit 2020; Recalcati 2020). ARDS is common in COVID-19 (Goh et al. 2020). ARDS is also described in dengue patients (Sen et al. 1999).

IgE mediated sensitization to coronavirus-like proteins will result in mast cell degranulation when exposed to the SARS-CoV-2 proteins. Specifically, mast cell degranulation by cross-linking of IgE bound to high affinity FceR1 receptors on the surface of mast cells results in the release of many mediators including histamine and ferritin (Ward et al. 2018). Histamine promotes release of IL-6 (Park et al. 2014). Elevated levels of ferritin and IL-6 are predictors for fatality in COVID-19 (Mehta et al. 2020). Such IgE triggered degranulation also results in the production of granulocyte-macrophage colony-stimulating factor (GM-CSF) (Okayama et al. 1998). This results in activation of the coagulation system and elevated D-dimer levels (Criado et al. 2013). The same cascade applies to secondary dengue infection.

Such striking similarity is to be expected because of the same underlying immunological mechanisms involved in both diseases. 


\section{The parasite connection}

In nature, the main role of the IgE antibody is defending against parasites. Many parasites in nature enter via the skin (malaria, hookworm). DENV is injected via the skin by a mosquito bite. Vaccines can contain viral proteins derived from coronavirus infected animals. These vaccines injected through the skin, program the immune system to recognize these viral proteins (and thus the viruses) as parasites (IgE mediated sensitization). The immune system therefore inappropriately mounts an anti-parasite response against the virus upon infection, along with an anti-viral response. So it is not surprising that some anti-parasitic medications (and anti allergy medications) seem to help by suppressing the inappropriate part of the immune response.

Parasites have evolved to produce numerous decoy proteins to confuse the human immune system as an evasive measure (Chauhan et al. 2017). As a result, the immune system is forced to produce IgE directed against numerous proteins thus diluting the response against parasite-specific proteins. Therefore in a population where parasite infections are common, IgE mediated response to any specific protein such as viral proteins would be weak. Now, with parasite infections being rare, this protection is lost. We have strong IgE mediated responses against viral proteins, once sensitized.

Hydroxychloroquine (HCQ), chloroquine (CQ) and ivermectin (IMC) are anti-parasite medications. There are indications that they may be beneficial in COVID-19 (GAUTRET et al. 2020; Chen et al. 2020) and dengue (Tricou et al. 2010). There is controversy over the antiviral activity of these drugs.

Both HCQ (Charous et al. 1998) and IMC (Steel et al.) have been shown to reduce IgE levels. So it does not come as a surprise that these anti-parasite drugs have beneficial effect on viral diseases involving IgE mediated immunopathological changes. IgE is now also involved in allergies. Antiallergy medications also can therefore help in these diseases (Chuamanochan 2019).

The Dengvaxia vaccine causes simultaneous IgE mediated sensitization against all four DENV serotypes. A natural infection will cause IgE mediated sensitization directed against only one DENV serotype at a time. A secondary infection by the same serotype virus will result in severe disease. Therefore, as expected, the probability of a severe secondary infection following the Dengvaxia vaccine is much higher thus resulting in more deaths among the vaccinated (Halstead 2017).

The exact same failure was observed in an experimental SARS-CoV vaccine in mice (Tseng et al. 2012). The mice developed IgE mediated sensitization to the SARS-CoV proteins following vaccination. The mice developed "Th2-type immunopathology suggesting hypersensitivity to SARSCoV components” when subsequently challenged with the virus.

So we have a consistent, repeating pattern of first injected exposure to SARS-CoV, dengue, influenza or coronavirus proteins resulting in IgE mediated sensitization directed against the viral proteins. Subsequent exposure to the viruses results in severe disease due to a viral infection concurrent with an allergic reaction. The first injection in the case of dengue virus can be a natural mosquito bite. In all other cases and in the case of the dengue vaccines, IgE mediated sensitization is iatrogenic and preventable. 


\section{Kounis syndrome and COVID-19}

Kounis syndrome is cardiac injury due to an allergic reaction (Kounis et al. 2018). Cardiac injury is reported in COVID-19 (Lala et al. 2020) and secondary dengue infections (Macedo 2018). Since COVID-19 severity and dengue secondary infections involve an allergic reaction, cardiac injury predictably occurs due to Kounis syndrome.

\section{Potential Treatments}

Mast cell stabilizers work at the main source and can prevent release of histamine, elevation of ferritin, IL-6, VEGF, D-dimer levels, etc. Neutrophils recruited to the infection site release histamine (Xu et al. 2006). Antihistamines can block some of the effects of histamine.

Vitamin C has an antihistamine effect (Johnston et al. 1992). HCQ improves IgE mediated asthma (Charous et al. 1998). Azithromycin has an anti-inflammatory effect on histamine induced inflammation (Ersoy et al. 2018). For these reasons, Vitamin C, HCQ and azithromycin can help in COVID-19 (GAUTRET et al. 2020; Chen et al. 2020).

\section{Data from Hydroxychloroquine trials that used overdoses must be discarded}

As for any drug, the dosage and timing are important for HCQ. Many major clinical trials like WHO SOLIDARITY and UK RECOVERY used near-lethal overdoses on very sick patients thus producing invalid results. The half life of HCQ is 40-50 days (Fan et al. 2015). So both dosage and duration of treatment are important. Properly conducted trials used the standard dose, $800 \mathrm{mg}$ loading dose on day one, followed by four more days at 400mg/day (Mercuro et al. 2020). The WHO SOLIDARITY/UK RECOVERY trials used 4X overdoses (RECOVERY Collaborative Group et al. 2020). They used twice the dose, for twice the duration. The Indian Council for Medical Research (ICMR) complained to the WHO about this overdose. Singapore used the standard dose in its trials. Focusing on trials that only used 400mg/day or less, the benefits of HCQ are obvious (Hernandez et al. 2020). The data from these invalid trials were allowed to pollute the good data, with the result that a perfectly good drug is being denied to patients.

\section{COVID-19 anaphylaxis misconceptions}

Anaphylaxis is commonly associated with food allergy, drug allergy or bee stings, etc. These are cases where the antigen dose exposure profile is a step function. So doctors and researchers are accustomed to rapid progression of symptoms. When the "allergen" is an infectious agent (SARS-CoV-2, DENV, influenza virus, etc.), the antigen dose ramps up over several days. So the progression is slower and symptoms that are not easily observed in regular anaphylaxis may be easily observed now. So people fail to recognize it as anaphylaxis. Some researchers perform a poor review by looking at only a single paper, miss the details and come to the wrong conclusion. As an example, Senna et al. (Senna et al. 2020) wrongly concluded that COVID-19 infection has negligible role in mast cell activation and anaphylaxis. This helps perpetuate the misconception, preventing appropriate treatments in COVID-19 thus leading to devastating consequences. 


\section{Confirmation of predictions}

Histamine release results in increased vascular permeability and pulmonary vascular dilatation. Pulmonary vascular dilatation results in hypoxemia (Reynolds et al. 2020), the most common symptom in COVID-19.

An allergic immune response involving increase in multiple type 2 (anti-helminth) effectors, IgE, eosinophils, IL-13 and IL-5 has been reported in severe COVID-19 (Lucas et al. 2020). IL-4expressing cells in the alveolar septa of patients with severe COVID 19 was reported. IL-4 is a type 2 cytokine (Motta Junior et al. 2020).

As predicted, numerous studies have shown the benefits of antihistamines (H1/H2 histamine blockers such as famotidine and cetirizine (Hogan et al. 2020; Freedberg et al. 2020; Janowitz et al. 2020; Mather et al. 2020).

So multiple, independent investigations confirm the common immunopathology involved and the successful use of treatments that were predicted.

\section{Conclusion}

COVID-19 severity is an iatrogenic disease caused by IgE mediated sensitization to proteins with high homology to SARS-CoV-2. Such proteins are present in vaccines due to components derived from infected animals as well as, excipients or residual non-target antigens. There are many indicators that mast cell degranulation, histamine release and the resulting immune cascade have a major role in COVID-19 and dengue infection severity. Mast cell stabilizers, antihistamines, Vitamin C, HCQ, azithromycin, ivermectin can address different aspects of this cascade and thus reduce disease severity. Disease mechanisms and immunopathology must be understood. Focusing on anti-viral action of drugs alone could be counter productive. For example, CQ had no effect on viraemia but decreased cases of DHF (Tricou et al. 2010). Immunopathology in COVID-19 and treatment were correctly predicted in Jan 2020 based on the understanding of the immunopathology in severe influenza infections. Predictions have been confirmed by numerous teams. A majority of the million COVID-19 deaths that have occurred were preventable. Continuing to ignore these findings will result in more preventable deaths. Mast cell stabilizers, antihistamines and other allergy, anaphylaxis treatments must be made standard for care immediately for COVID-19 (as well as for dengue and influenza), to avoid more morbidity and mortality. No clinical trials are needed because immunopathology is understood and proven treatment protocols (Lieberman et al. 2005) exist.

\section{References}

Ahmed SS, Volkmuth W, Duca J, et al (2015) Antibodies to influenza nucleoprotein cross-react with human hypocretin receptor 2. Sci Transl Med 7:294ra105.

https://doi.org/10.1126/scitranslmed.aab2354

Altschul SF, Madden TL, Schäffer AA, et al (1997) Gapped BLAST and PSI- BLAST: a new generation of protein database search programs. Nucleic Acids Res 25:3389-3402. https://doi.org/ 10.1093/nar/25.17.3389 
Arumugham V (2018) Influenza vaccines and dengue-like disease. In: BMJ.

https://www.bmj.com/content/360/bmj.k1378/rr-15. Accessed 14 Oct 2020

Arumugham V (2015) Evidence that Food Proteins in Vaccines Cause the Development of Food Allergies and Its Implications for Vaccine Policy. J Dev Drugs 04:1-3. https://doi.org/10.4172/2329-6631.1000137

CDC (2015) Centers for Disease Control and Prevention Epidemiology and Prevention of VaccinePreventable Diseases,13th Edition.

https://www.cdc.gov/vaccines/pubs/pinkbook/downloads/appendices/appdx-full-b.pdf. Accessed 17 Jan 2020

Charous BL, Halpern EF, Steven GC (1998) Hydroxychloroquine improves airflow and lowers circulating IgE levels in subjects with moderate symptomatic asthma. J Allergy Clin Immunol 102:198-203. https://doi.org/10.1016/S0091-6749(98)70086-7

Chauhan VM, Scurr DJ, Christie T, et al (2017) The physicochemical fingerprint of Necator americanus. PLoS Negl Trop Dis 11:e0005971. https://doi.org/10.1371/journal.pntd.0005971

Chen Z, Hu J, Zhang Z, et al (2020) Efficacy of hydroxychloroquine in patients with COVID-19: results of a randomized clinical trial. medRxiv 2020.03.22.20040758. https://doi.org/10.1101/2020.03.22.20040758

Chuamanochan M (2019) A case of dengue fever presenting with acute urticaria. Asian Pacific J Allergy Immunol. https://doi.org/10.12932/ap-150419-0539

Criado PR, Antinori LCL, Maruta CW, dos Reis VMS (2013) Evaluation of D-dimer serum levels among patients with chronic urticaria, psoriasis and urticarial vasculitis. An Bras Dermatol 88:355-360. https://doi.org/10.1590/abd1806-4841.20131532

Davidsson A, Eriksson JC, Rudblad S, Brokstad KA (2005) Influenza Specific Serum IgE is Present in Non-Allergic Subjects. Scand J Immunol 62:560-561. https://doi.org/10.1111/j.13653083.2005.01710.x

Ersoy B, Aktan B, Kilic K, et al (2018) The anti-inflammatory effects of erythromycin, clarithromycin, azithromycin and roxithromycin on histamine-induced otitis media with effusion in Guinea pigs. J Laryngol Otol 132:579-583. https://doi.org/10.1017/S0022215118000610

Fan H, Ma Z, Chen J, et al (2015) Pharmacokinetics and Bioequivalence Study of Hydroxychloroquine Sulfate Tablets in Chinese Healthy Volunteers by LC-MS/MS. Rheumatol Ther 2:183-195. https://doi.org/10.1007/s40744-015-0012-0

Freedberg DE, Conigliaro J, Wang TC, et al (2020) Famotidine Use Is Associated With Improved Clinical Outcomes in Hospitalized COVID-19 Patients: A Propensity Score Matched Retrospective Cohort Study. Gastroenterology 159:1129-1131.e3. https://doi.org/10.1053/j.gastro.2020.05.053 
GAUTRET P, LAGIER JC, PAROLA P, et al (2020) Hydroxychloroquine and Azithromycin as a treatment of COVID-19: preliminary results of an open-label non-randomized clinical trial. medRxiv 2020.03.16.20037135. https://doi.org/10.1101/2020.03.16.20037135

Goh KJ, Choong MC, Cheong EH, et al (2020) Rapid Progression to Acute Respiratory Distress Syndrome: Review of Current Understanding of Critical Illness from COVID-19 Infection. Ann Acad Med Singapore 49:1-9

Goldis M, Bardina L, Lin J, Sampson HA (2010) Evaluation of Egg Protein Contamination in Influenza Vaccines. J Allergy Clin Immunol. https://doi.org/10.1016/j.jaci.2009.12.507

Halstead SB (2017) Dengvaxia sensitizes seronegatives to vaccine enhanced disease regardless of age. Vaccine 35:6355-6358. https://doi.org/10.1016/j.vaccine.2017.09.089

Hernandez A V., Roman YM, Pasupuleti V, et al (2020) Update Alert 2: Hydroxychloroquine or Chloroquine for the Treatment or Prophylaxis of COVID-19. Ann Intern Med. https://doi.org/10.7326/120-1054

Hogan RB, Hogan RB, Cannon T, et al (2020) Dual-histamine receptor blockade with cetirizine famotidine reduces pulmonary symptoms in COVID-19 patients. Pulm Pharmacol Ther 63:101942. https://doi.org/10.1016/j.pupt.2020.101942

Janowitz T, Gablenz E, Pattinson D, et al (2020) Famotidine use and quantitative symptom tracking for COVID-19 in non-hospitalised patients: A case series. Gut 69:1592-1597. https://doi.org/10.1136/ gutjnl-2020-321852

Johnston CS, Martin LJ, Cai X (1992) Antihistamine effect of supplemental ascorbic acid and neutrophil chemotaxis. In: Journal of the American College of Nutrition. pp 172-176

Joob B, Wiwanitkit V (2020) COVID-19 can present with a rash and be mistaken for Dengue. J Am Acad Dermatol 0: https://doi.org/10.1016/j.jaad.2020.03.036

Justiz Vaillant AA, Zito PM (2018) Hypersensitivity Reactions, Immediate. StatPearls Publishing

Kim MJ, Shim DH, Cha H-R, et al (2020) Delayed-Onset Anaphylaxis Caused by IgE Response to Influenza Vaccination. Allergy Asthma Immunol Res 12:359. https://doi.org/10.4168/aair.2020.12.2.359

Koraka P, Murgue B, Deparis X, et al (2003) Elevated levels of total and dengue virus-specific immunoglobulin E in patients with varying disease severity. J Med Virol 70:91-98. https://doi.org/ 10.1002/jmv.10358

Kounis NG, Cervellin G, Koniari I, et al (2018) Anaphylactic cardiovascular collapse and Kounis syndrome: systemic vasodilation or coronary vasoconstriction? Ann Transl Med 6:332-332. https://doi.org/10.21037/atm.2018.09.05 
Lala A, Johnson KW, Januzzi JL, et al (2020) Prevalence and Impact of Myocardial Injury in Patients Hospitalized With COVID-19 Infection. J Am Coll Cardiol 76:533-546.

https://doi.org/10.1016/j.jacc.2020.06.007

Lieberman P, Kemp SF, Oppenheimer J, et al (2005) The diagnosis and management of anaphylaxis: An updated practice parameter. J. Allergy Clin. Immunol. 115:S483-523

Lucas C, Wong P, Klein J, et al (2020) Longitudinal analyses reveal immunological misfiring in severe COVID-19. Nature 584:463. https://doi.org/10.1038/s41586-020-2588-y

Macedo A (2018) Abstract 19104: Troponin Elevation is Strongly Associated With Death in Dengue Patients With Cardiac Involvement | Circulation.

https://www.ahajournals.org/doi/10.1161/circ.136.suppl_1.19104. Accessed 31 May 2020

Mather JF, Seip RL, McKay RG (2020) Impact of Famotidine Use on Clinical Outcomes of Hospitalized Patients With COVID-19. Am J Gastroenterol 115:1617-1623. https://doi.org/10.14309/ajg.0000000000000832

Mehta P, Mcauley DF, Brown M, et al (2020) Correspondence COVID-19 : consider cytokine storm syndromes and. Lancet 6736:19-20. https://doi.org/10.1016/S0140-6736(20)30628-0

Mercuro NJ, Yen CF, Shim DJ, et al (2020) Risk of QT Interval Prolongation Associated with Use of Hydroxychloroquine with or without Concomitant Azithromycin among Hospitalized Patients Testing Positive for Coronavirus Disease 2019 (COVID-19). JAMA Cardiol. https://doi.org/10.1001/jamacardio.2020.1834

Míguez-Burbano MJ, Jaramillo CA, Palmer CJ, et al (1999) Total Immunoglobulin E Levels and Dengue Infection on San Andrés Island, Colombia. Clin Diagn Lab Immunol 6:624 LP - 626

Motta Junior J da S, Miggiolaro AFR dos S, Nagashima S, et al (2020) Mast Cells in Alveolar Septa of COVID-19 Patients: A Pathogenic Pathway That May Link Interstitial Edema to Immunothrombosis. Front Immunol 11:574862. https://doi.org/10.3389/fimmu.2020.574862

Mutiara, Koh SCL, Bachtiar A, Hariman H (2019) The vascular endothelium in patients with dengue haemorrhagic fever. Open Access Maced J Med Sci 7:2221-2225. https://doi.org/10.3889/oamjms.2019.621

Nagao M, Fujisawa T, Ihara T, Kino Y (2016) Highly increased levels of IgE antibodies to vaccine components in children with influenza vaccine-associated anaphylaxis. J Allergy Clin Immunol 137:861-867. https://doi.org/10.1016/j.jaci.2015.08.001

Nakayama T, Kumagai T, Nishimura N, et al (2015) Seasonal split influenza vaccine induced IgE sensitization against influenza vaccine. Vaccine 33:6099-6105.

https://doi.org/10.1016/j.vaccine.2015.05.106

Okayama Y, Kobayashi H, Ashman LK, et al (1998) Human lung mast cells are enriched in the capacity to produce granulocyte-macrophage colony-stimulating factor in response to IgE-dependent 
stimulation. Eur J Immunol 28:708-15. https://doi.org/10.1002/(SICI)15214141(199802)28:02<708::AID-IMMU708>3.0.CO;2-A

Orsi FA, Angerami RN, Mazetto BM, et al (2013) Reduced thrombin formation and excessive fibrinolysis are associated with bleeding complications in patients with dengue fever: A casecontrol study comparing dengue fever patients with and without bleeding manifestations. BMC Infect Dis 13:350. https://doi.org/10.1186/1471-2334-13-350

Park IH, Um JY, Cho JS, et al (2014) Histamine promotes the release of interleukin-6 via the H1R/p38 and NF-kB pathways in nasal fibroblasts. Allergy, Asthma Immunol Res 6:567-572. https://doi.org/10.4168/aair.2014.6.6.567

Rachman A, Rinaldi I (2006) Coagulopathy in dengue infection and the role of interleukin-6. Acta Med. Indones. 38:105-108

Recalcati S (2020) Cutaneous manifestations in COVID-19: a first perspective. J Eur Acad Dermatology Venereol. https://doi.org/10.1111/jdv.16387

RECOVERY Collaborative Group, Horby P, Mafham M, et al (2020) Effect of Hydroxychloroquine in Hospitalized Patients with Covid-19. N Engl J Med NEJMoa2022926. https://doi.org/10.1056/NEJMoa2022926

Reynolds AS, Lee AG, Renz J, et al (2020) Pulmonary Vascular Dilatation Detected by Automated Transcranial Doppler in COVID-19 Pneumonia. Am J Respir Crit Care Med. https://doi.org/10.1164/rccm.202006-2219le

Richet C (1913) Charles Richet - Nobel Lecture: Anaphylaxis - NobelPrize.org. https://www.nobelprize.org/prizes/medicine/1913/richet/lecture/. Accessed 12 Feb 2019

Sen MK, Ojha UC, Chakrabarti S, Suri JC (1999) Dengue hemorrhagic fever (DHF) presenting with ARDS. Indian J Chest Dis Allied Sci 41:115-9

Senna G, Caminati M, Castells M (2020) Editorial: Reconsidering anaphylaxis at the time of COVID19 pandemic. Curr Opin Allergy Clin Immunol 20:429-430. https://doi.org/10.1097/ACI.0000000000000682

Smith-Norowitz TA, Wong D, Kusonruksa M, et al (2011) Long term persistence of IgE anti-influenza virus antibodies in pediatric and adult serum post vaccination with influenza virus vaccine. Int $\mathrm{J}$ Med Sci 8:239-44

Sridhar A, Sunil Kumar BM, Rau A, Rau ATK (2017) A Correlation of the Platelet Count with DDimer Levels as an Indicator for Component Therapy in Children with Dengue Hemorrhagic Fever. Indian J Hematol Blood Transfus 33:222-227. https://doi.org/10.1007/s12288-016-0686-7

Steel C, Lujan-Trangay A, Gonzalez-Peralta C, et al Immunologic Responses to Repeated Ivermectin Treatment in Patients with Onchocerciasis. J. Infect. Dis. 164:581-587 
Tricou V, Minh NN, Van TP, et al (2010) A Randomized Controlled Trial of Chloroquine for the Treatment of Dengue in Vietnamese Adults. PLoS Negl Trop Dis 4:e785.

https://doi.org/10.1371/journal.pntd.0000785

Tseng C Te, Sbrana E, Iwata-Yoshikawa N, et al (2012) Immunization with SARS coronavirus vaccines leads to pulmonary immunopathology on challenge with the SARS virus. PLoS One 7:. https://doi.org/10.1371/journal.pone.0035421

Van de Weg CAM, Huits RMHG, Pannuti CS, et al (2014) Hyperferritinaemia in Dengue Virus Infected Patients Is Associated with Immune Activation and Coagulation Disturbances. PLoS Negl Trop Dis 8:. https://doi.org/10.1371/journal.pntd.0003214

Ward BR, Hicks M, Johnson J-M, Myo YPA (2018) Ferritin Particles Accumulate in Human Mast Cell Secretory Granules and Are Released upon FceRI-mediated Activation. J Allergy Clin Immunol 141:AB229. https://doi.org/10.1016/j.jaci.2017.12.722

Xu X, Zhang D, Zhang H, et al (2006) Neutrophil histamine contributes to inflammation in mycoplasma pneumonia. J Exp Med 203:2907-2917. https://doi.org/10.1084/jem.20061232

Yan G, Lee CK, Lam LTM, et al (2020) Covert COVID-19 and false-positive dengue serology in Singapore. Lancet Infect. Dis. 0

Zhang W, Zhao Y, Zhang F, et al (2020a) The use of anti-inflammatory drugs in the treatment of people with severe coronavirus disease 2019 (COVID-19): The experience of clinical immunologists from China. Clin. Immunol. 214

Zhang Y, Xiao M, Zhang S, et al (2020b) Coagulopathy and Antiphospholipid Antibodies in Patients with Covid-19. N Engl J Med NEJMc2007575. https://doi.org/10.1056/NEJMc2007575 